\title{
Flexibility at the Workplace: Does it impact empowerment and Quality of Life?
}

\author{
Geetha Subramaniam¹, Peck-Leong Tan², \\ Balasundram Maniam ${ }^{3}$, Ershad Ali ${ }^{4}$ \\ ${ }^{1}$ Faculty of Business Management, Universiti Teknologi MARA, 40450 Shah Alam, Malaysia \\ ${ }^{2}$ Arshad Ayub Graduate Business School, Universiti Teknologi MARA, Shah Alam, 40450, Selangor Malaysia \\ ${ }^{3}$ Department of Finance, Sam Houston State University, , TX 77340,United States \\ ${ }^{4}$ AIS,St.Helens,Auckland,New Zealand \\ geethamaniam@gmail.com
}

\begin{abstract}
Empowering women to participate in economic life is one way to improve the quality of life for women and families. However, many Malaysian women exit from the formal labour market resulting in women's participation stagnating at around 40 percent since the 1990s. Using a mixed method approach, this study examines whether workplace flexibility may impact women's empowerment and quality of life. A sample of 400 female employees from the services sector answered a self-administered questionnaire complemented by 30 interviews. Multivariate analysis and structured interviews showed that a workplace designed with flexibility has a positive impact on women's empowerment and quality of life.

Keywords: Empowerment; Flexible working arrangements; Quality of life; Workplace flexibility; Women in the labour market.

eISSN 2398-4295 @ 2018. The Authors. Published for AMER ABRA cE-Bs by e-International Publishing House, Ltd., UK. This is an open-access article under the CC BY-NC-ND license (http://creativecommons.org/licenses/bync-nd/4.0/). Peer-review under responsibility of AMER (Association of Malaysian Environment-Behaviour Researchers), ABRA (Association of Behavioural Researchers on Asians) and CE-Bs (Centre for EnvironmentBehaviour Studies), Faculty of Architecture, Planning \& Surveying, Universiti Teknologi MARA, Malaysia. http://dx.doi.org/10.21834/ajbes.v3i11.105
\end{abstract}




\subsection{Introduction}

Empowering women to participate in economic life is one way to improve the quality of life for women, families and communities. However, unable to juggle work and home, many women exit from the formal labour market in Malaysia in spite of the human capital investment they acquire in terms of education and training. One of the objectives in The Tenth Malaysian Plan is to increase the female labour force participation from the current 47.6 percent to 55 percent by 2015. While the United Nations Report (2011) identified workplace rigidity and child care responsibilities as major issues of concern in women's empowerment and quality of life, women's participation in Malaysia has been stagnating at around 40 percent in the last three decades.

Empowerment means women are at an advantage by the way power relations presently shape their decisions, opportunities and well-being. Working women therefore would be more empowered to make decisions pertaining to their lives and the household, as a whole. This, in turn, directly impacts women's quality of life as women's empowerment is the essence of greater freedom and control over important decisions that affect their lives. Empowerment outcomes for women in this study were defined in terms of their role in economic empowerment, household empowerment and social empowerment.

On the other hand, workplace flexibility is measured by flexible working arrangements (FWAs) at the workplace. Examples of quality FWAs include: varying starting and finishing time; annualised hours or term time working; part-time working; working from home or teleworking; job sharing; selecting or influencing own rosters or shifts; flexible break provisions and flexible leave/time off provisions, both paid and unpaid.

This paper attempts to understand the low participation of women in the labour force in Malaysia by examining the possibility of workplace reforms and its impact on women's empowerment and quality of life. This is further discussed by investigating whether workplace flexibility may have an impact on women's choice to participate in the labour force. This paper finally concludes with discussions on how workplaces designed with family friendly policies and other measures might have an effect on women's continued participation in the labour market.

\subsection{Literature Review}

\section{Workplace Flexibility and Female Labour Market}

While Durand (1975) argues that the "twin peak" phenomenon in most countries is separated by a trough of lower rates in the central age groups, this varies between nations and is closely related to marriage and the family. Kottis and Dimelis (1992) adopted the model of Mincer and Becker that women's decision to participate in the labour force is the result of utility maximising behaviour which involves the choice between work, domestic activities and leisure.

While the neo-classical theory of household choice and resource allocation are highly useful in explaining female labour force participation of women, it is obvious that some factors 98 
will have a greater influence on women's decision to participate in paid work outside the home (Borjas, 2009). According to Glass and Estes (1997), women's entrance into the labour market in large numbers has aggravated incompatibilities between employers and family interests. Besides, consequences of work stress range from absenteeism, poor job performance, and job dissatisfaction to high accident and high turnover rate (Ahmad et al., 2012).

However, the fact remains that inflexibility at the workplace and inability to juggle work and career are critical factors why married women leave the labour force (Kaur, 2004). Chow and Cheung (2013), in a study in Hong Kong, explained the effectiveness of three measures - namely flexible work time, a five-day work week and career breaks - in reducing both worklife conflicts and their negative consequences.

\section{Flexibility at the Workplace}

Flexibility at the workplace is about how work is managed in the workplace so that both the employees and businesses benefit. FWAs are often considered an essential component of 'family-friendly policies' and are widely seen as ideal means to achieve a more balanced work and home life. It is also regarded powerful and has a positive effect on the employee's attitude and job satisfaction (Lietchy \& Anderson, 2007). According to Borjalilou et al. (2013), women face many constraints as they choose how to balance work and family and what priority they will give to one over the other at particular times (Kumra, 2010). Wattis and James (2013), in their study, state that women attempt to contain the domestic sphere so as not to disrupt paid work and are subject to emotional conflicts inherent to combining dual roles.

FWAs help women to juggle work and home by allowing more time, however, it tends to perpetuate social constructs. Zimmerman (2003), on the other hand, says that in order to be successful in balancing work and family life, working mothers have been found to be making several marital partnerships with their spouses inclusive of sharing house work, mutual involvement in child care, joint decision-making, equal financial influence and sharing emotional stress. Furthermore, according to Galea et al. (2013), the more family responsibilities women have, the more they tend to perceive flexible working hours as a necessity rather than an extra benefit.

\section{Empowerment}

All over the world, women employees struggle in the workplace trying to thrive in their careers and their family lives. Anthias and Mehta (2003), in their study, found it was certain that economic independence gave women a sense of empowerment. While women bring money back home as an income earner, they also play another role of the 'woman of the house' who has caring responsibilities as well. Asian women who are working, generally feel guilty about devoting less time with family and maternal responsibilities. However, as FWAs allow her to work and perform other household responsibilities, the balance of power shifts a little to her advantage empowering her with greater decision making an influence and having a considerable say in how the household money is spent. In a recent study of working women 
in Asian countries by Zhu et al. (2012), it was found that women's employment concerns and working conditions remain as issues of concern.

Leveraging the idea of workplace flexibility as a strategic approach empowers women and is a win-win situation for employers and women employees. The Trade Union Congress, UK, based on its results on a study in 2012, found that despite a recession, working from home was taken up especially among women employees (TUC, 2013).

Existing literature shows that women's participation in the labour force is affected to a certain extent by their workplace environment which has a bearing on their empowerment status and quality of life. Therefore, to increase women's participation in paid labour, it might be pertinent to look at workplace flexibility which is the main focus of this study.

\subsection{Methodology}

This study was conducted in the Klang Valley, the central business hub of Malaysia, using a sequential mixed method strategy. Firstly, a quantitative method adapted from Almer, Cohen \& Single (2003) was used followed by a qualitative method involving detailed interviews with 30 identified participants from the same sample. Based on the statistics from the Labour Force Survey Report Malaysia (2011) six sub-groups in the services sector which had a substantial number of working women were identified. This was further narrowed down by using the Malaysian Employers Federation list, where organisations in the services sector which had FWAs and non-FWAs were identified. The purposing sampling technique was used, and a total of fourteen organisations which have FWAs were identified. To reduce selection bias, respondents were selected at random by the Human Resource Manager. A total of 500 questionnaires were distributed equally to FWA organisations and non-FWA organisations. The total sample size was 396 , with a response rate of 57 percent from FWA organisations and 43 percent from non-FWA organisations.

The questionnaire consisted of 4 parts: Part A consisted of 5 items on the demographic profile; Part B consisted of 2 items on income level; Part $C$ consisted of 3 items on family responsibilities and Part $D$ consisted of questions on empowerment and quality of life. Using the Delphi technique and focus group discussion with women's groups and women employees, indicators of quality of life, namely empowerment and lifestyles, were identified. There were seven items for empowerment and three items for lifestyles which were indicated on a scale of 1 (Strongly Disagree) to 5 (Strongly Agree) on their perception on statements with regard to the two selected indicators. Data was analysed using the SPSS 20 software. Descriptive statistics and cross tabulations were used to support the findings.

The quantitative analysis was further reinforced by doing a qualitative interview using structured interviews. From the thirty respondents, 50 percent of them were volunteers while the balance 50 percent was identified by the human resource personnel of the organisations. Each interview lasted for an hour and respondents were asked to narrate how they carry out their dual roles of paid labour and unpaid labour on any particular day. This was to get a deeper insight into female workers' experience of their daily activities. In this paper, we 
highlight how the respondents relate workplace flexibility to their quality of life, specifically in terms of empowerment and lifestyles. Using thematic analysis, interviews were transcribed.

\subsection{Results and Discussions}

\section{Respondents' profile}

Of the 396 respondents who participated in the survey, the majority of the women were in the youngest age group (20-29 years), with nearly 40 percent in the 30-39 years age group which conforms to the trend of the female labour force participation in Malaysia. The educational level shows that all of them had a minimum of eleven years of schooling and the majority of them (72\%) possess a basic bachelor's degree. Most of the respondents earn an income below RM3000 per month with 26 percent of them earning more than RM4000 (1USD is equivalent to RM3.1). A very large proportion of the respondents $(50 \%)$ were at the executive or officer level with an encouraging 18 percent at the management/professional level.

In terms of marital status, 60 percent of the respondents are married women, with 83 percent of them having children, whereby 50 percent of them had at least two children. The majority of the respondents ( 86 percent) were interested in FWAs at their workplace. The hypothesis tested was to see whether FWAs will have any effect on women's quality of life measured in terms of empowerment and lifestyles.

As for the qualitative research, interviews were conducted with 30 women, which constituted of 15 women from FWA organisations and 15 women from non-FWA organisations. These women were from the same 14 organisations in the services sector and their ages ranged from 26 to 52 years with a mean age of 35 years. A total of 23 respondents $(77 \%)$ were married, but only 20 had children while two were newly married couples and one was a widow. Among the respondents who had children, eleven $(55 \%)$ had at least one child below six years old and ten $(50 \%)$ had at least one school-going child. There were six respondents with college-going children or working adults. The sample was urbanised, and Malaysia's main multiethnic society was represented with thirteen Malays, seven Chinese and ten Indians.

\section{Quantitative research findings}

In this study, the independent variable 'working arrangement' was being tested against the two dependent variables: empowerment and lifestyles, to determine whether FWAs have an effect on the two aspects of women's lives. As there are two dependent variables, a MANOVA or Multivariate Analysis of variance was carried out.

For each of the indicators, an exploratory factor analysis, a dimension reduction technique, was performed using a varimax rotation (Hair, et al., 2010). Based on the eigenvalues, only one factor with value more than 1 was retained in each of the two constructs, namely, Empowerment and Lifestyles. In this analysis, the KMO value for empowerment was 0.8 
which explained more than 78 percent of the variability in the data. The factor loading, KMO values and explained variation for the two constructs are as shown in Table 1.

Table 1: Summary results from factor analysis

\begin{tabular}{|llll|}
\hline Construct & No of Items & KMO & Explained variation \\
\hline Empowerment & 7 & 0.8 & $78 \%$ \\
Lifestyles & 3 & 0.7 & $82 \%$ \\
\hline
\end{tabular}

The same procedure was done for lifestyles, and the KMO value was 0.7 , which shows that the items which were expected to measure lifestyles explained the factors well and gave a factor which explains more than 82 percent of the variability in the data. Using the MANOVA test, it was found that the mean for empowerment was $p=0.035$, while the mean for lifestyles was 0.34 , which means that there was no significant difference in the lifestyles of women working in FWA organisations or non-FWA organisations. The MANOVA test showed that working arrangements had an effect on women's quality of life in terms of empowerment but not lifestyles as shown in Table 2.

Table 2: Manova table showing significant values for working arrangements and the effect on women's quality of life

\begin{tabular}{|lllllll|}
\hline \multirow{2}{*}{ Source } & Dependent & \multicolumn{2}{l}{ Type III Sum } & & & \\
Variable & of Squares & df & Mean Square & F & Sig. \\
\hline Work type & Empowerment & 4.401 & 1 & 4.401 & 4.501 & .035 \\
& Lifestyles & 0.913 & 1 & .913 & 0.917 & .339 \\
\hline
\end{tabular}

The analysis shows that women working in FWA organisations experience more empowerment compared to the women working in non-FWA organisations. They can manage work, household chores and family responsibilities better. These women are also able to juggle work and home more efficiently and spend more time for family.

However, FWAs did not have any significant effect on lifestyles of the working women. Upon a further analysis of cross tabulation, it was interestingly found that marital status had an impact on working women's lifestyles. Women who were single and had no household responsibilities had more time for themselves in terms of recreation and socialising. To reconfirm the analysis and get a more vivid explanation of the findings, a qualitative interview was conducted and the findings are as explained in the next section.

\section{Qualitative research findings}

The key concept in this section was to capture how FWAs are linked to women's juggling the double burden. The thematic analysis from the interviews revealed that women working in organisations which have FWAs have more flexibility to manage children, work and home. Household empowerment was noted among respondents who worked in organisations which 
practice FWAs. As for economic empowerment, the respondents were explicitly asked the question "Who makes the decisions regarding finance, purchase and ownership of assets in your family?" Social empowerment was captured in this study based on the respondents' stories of their mode of travel to work, owning a vehicle and visits to friends and relatives' houses.

Respondents in FWA organisations were able to organise themselves better in terms of managing work and home. They had more control over domestic matters and also their personal lives. The open-ended questions were able to bring out value because they illuminated the issues of quality of life of the working women.

\subsection{Conclusion}

Broadly speaking, the present analysis shows that FWAs have a positive effect on women's quality of life in terms of household empowerment and their autonomy and capability of making decisions which might have an effect on their decisions to work in paid labour. The main conclusions which can be drawn from this study are:

- Firstly, both the quantitative and qualitative analysis reveal that workplace flexibility has an impact on women's empowerment but not on their lifestyles. This influences their quality of life both directly and indirectly.

- Secondly, household empowerment sometimes measured in a narrow sense is seen as the ability to juggle work and home better with FWAs and is important for women to experience it. Juggling work and household chores without any help is the main problem for working women. Besides, commuting time regardless of workplace arrangements is an influential predictor of women's quality of life.

- Thirdly, though all the women, irrespective of their working arrangements, had an economic empowerment in joint decision-making regarding finances and social empowerment in terms of visiting friends and relatives, women with independent sources of income have a louder voice within a household, and that was perceived to improve their quality of life. These findings were also revealed in an earlier study by Subramaniam et al. (2010), where 60 percent of the women who exit the labour force wanted to return to work after their children were above five years old in order to be economically independent.

- Finally, in terms of lifestyles, even though workplace flexibility did not have any significant effect on lifestyles, marital status did. This was due to the patriarchal values which continue to persist in the Malaysian culture.

Although this study has several notable contributions to explaining the low participation of women in the labour force in Malaysia, there are some limitations where several issues need to be investigated further. Firstly, the sample size could be increased. Secondly, as this study focused on the services sector, further studies could be done in the primary and secondary sectors in Malaysia.

As Malaysia's vision is to become a high-income economy, the required human capital must be creative and innovative. One can begin to see the mindset change among the 
younger, educated generation, but a lot more needs to be done to achieve a balanced life at home.

\section{Implications and Policy Recommendations}

The implications that can be made from this study are multiple. The most apparent one is that FWAs provide workplace flexibility and can be a possible tool to retain women in the labour force as it empowers women with more time to juggle the double burden of work and home. Even though women as income earners have elevated from a totally subordinate status within a household, they now have to play a 'double role', which is that of a homemaker and income earner. Unfortunately, complex processes of cultural and traditional values with a mindset that continues allowing patriarchal views reinforce such a position of a woman in the household.

There are a few policy recommendations that can be made at this point. The first policy recommendation here would be the designing and implementation of working arrangements which are more family-friendly to help women to attain a better quality of life and empowerment. Working from home, flexible working time and permanent part-time are examples of FWAs that may provide women with caring responsibilities, to juggle their double burden and feel empowered to do so. Secondly, the government has to provide an enabling environment in a more institutionalised way to ensure that the child care system is affordable. In this matter, the state should play a more proactive role in implementing, regulating and monitoring child care and after-school care centres which provide quality care for children, thus enabling their mothers to be able to carry out their work at peace. Next, though FWAs are very beneficial to women, they do tend to have limitations as well. Therefore, it is pertinent to offer FWAs not as a comprehensive package but on a case-to-case basis. Last but not least, the challenge of successful implementation of FWAs lies collectively on employers, policymakers, and society, in general. It also means doing away with the stereotype of the woman as a homemaker and moving towards a fair, broad and wholesome level of thinking. It cannot be stressed more that empowerment truly has to start from home.

As Malaysia moves towards achieving an industrialised nation status, many policies set to bring women into the labour force show the government's increasing concern on this issue. For these effective policies to be successful, a change in mindset is highly crucial as women's empowerment starts from the home. However, the equally significant issue of concern is a need for a paradigm shift in the designing of a working environment which facilitates women's juggling of paid and unpaid labour.

\section{Acknowledgement}

We are grateful for the financial grants from RAGS (168/2012) from Ministry of Higher Education, Malaysia. Special thanks also for assistance provided by Faculty of Business Management and Arshad Ayub Graduate Business School, Universiti Teknologi MARA, Malaysia. 


\section{References}

Almer, E.D, Cohen, J.R \& Single, L.E.(2007). Factors Affecting the Choice to Participate in Flexible Work Arrangements, Journal of Auditing, 22, (1), 69-91.

Anthias, F., \& Mehta, N. (2003). The intersection between gender, the family and self-employment: the family as a resource. International Review of Sociology/Revue internationale de sociologie, 13(1), 105-116.

Borjalilou, S, Nazemi, S, Mortazawi, S, Rahmanseresht, H (2013), Reflections of Post Feminist Viewpoints on Female Related Issues in Organisations, Interdisciplinary Journal of Contemporary Research In Business, February 2013, Vol 4, No 10

Borjas,G. (2009) Labor Economics, McGraw Hill, 5th Edition.

Chou, K. L., \& Cheung, K. C. K. (2013). Family-friendly policies in the workplace and their effect on work-life conflicts in Hong Kong. The International Journal of Human Resource Management, 1-14.

Durand, J. D., (1975). The Labor Force in Economic Development - A Comparison of International Census, 19461966, Princeton: Princeton University Press.

Galea, C., Houkes, I., \& De Rijk, A. (2013). An insider's point of view: how a system of flexible working hours helps employees to strike a proper balance between work and personal life. The International Journal of Human Resource Management, 1-22.

Glass, J. L., \& Estes, S. B. (1997). The Family Responsive Workplace. Annual review of sociology, 289-313..

Hair,J.F., Black, W.C., Babin, B.J., \& Anderson. R. E., (2010) Multivariate Data Analysis A Global Perspective (Seventh Edition), Pearson Prentice Hall, New Jersey, USA,

Kaur, Amarjit, (2004). Costed Not Valued: Women Workers In Industrialising Asia, New York, Palgrave Macmillan,

Kottis,P \& Dimelis, S (1992). Labour Force Participation and Earnings of Women University Graduates in Greece: a Two-step Analysis, International Journal of Manpower, 13(9), 47 - 64.

Liechty, J. M., \& Anderson, E. A. (2007). Flexible Workplace Policies: Lessons from the Federal Alternative Work Schedules Act", Family Relations, (56), 304-317.

Lijphart, Arend, (1971). Comparative Politics and the Comparative Method, American Political Science Review, Vol. $65,(3)$.

Malaysia, Labour Force Survey Report, Department of Statistics, Malaysia. Various Issues.2010,2011,2012.

McDowell, L. M. (2013). Skills and Labour market change.

Noor, S.M. \& Abdullah, M.A. (2012) . Quality Work Life among Factory Workers in Malaysia. Procedia - Social and Behavioral Sciences, 35, $739-745$.

Subramaniam, G, Mohamad, S \& Selvaratnam, D. P. (2010). "Why Do Some Women Leave The Labour Force?- A Micro Perspective from Malaysia", Economic Bulletin, Volume 11.

TUC (2013) Home-working on the increase despite the recession, retrieved from http://www.tuc.org.uk/workplace/tuc-22217-f0.cfm 
UNESCAP (2011). United Nations Economic and Social Commission for Asia and the Pacific, annual report.

United Nations (2010) The World's Women 2010 Trends and Statistics.

Wattis, L., \& James, L. (2013). Exploring order and disorder: Women's experiences balancing work and care. European Journal of Women's Studies.

Zhu, H., Khan, H. G. A., \& llyas, M. (2012). Challenges and risks faced by the working women in government organizations: An insight from Asian countries. African Journal of Business Management, 6(45), 11368-11374.

Zimmerman, T. S. (2003). Intimate partnership: Foundation to the successful balance of family and work. American Journal of Family Therapy, 31(2), 107-124. 